\title{
EFEKTIVITAS PEMBELAJARAN COOPERATIPE INTEGRATED READING AND COMPOCITION (CIRC) UNTUK MENINGKATKAN PEMAHAMAN KONSEP BELAJAR MATEMATIKA SISWA PADA MATERI PERSAMAAN LINEAR DUA VARIABEL DI KELAS X SMA NEGERI 2 TORGAMBA TAHUN PEMBELAJARAN 2017/2018
}

\author{
Nuranni Hasmiah Nasution \\ Mahasiswa Program Studi Pendidikan Matematika STKIP Labuhanbatu \\ STKIP Labuhanbatu,JIn. SM. Raja No. 126A, KM, 3.5 Aek Tapa, Rantauprapat \\ Diterima (Oktober 2018) dan disetujui (Nopember 2018)
}

\begin{abstract}
Abstrak
Penelitian ini bertujuan untuk mengetahui apakah terdapat peningkatan pemahaman konsep dan untuk mengetahui bagaimana proses jawaban siswa. Jenis penelitian ini adalah semi eksperimen (quasi eksperimen). Data yang diperoleh thitung $=6,466$. Setelah membandingkan harga thitung dengan harga tabel dengan taraf nyata $\alpha=0,01$ untuk daftar distribusi t diperoleh tabel $=2,856$, karena thitung tidak terletak diantara - 2,856 dan 2,856 maka Ho ditolak dengan kata lain Ha diterima. Dengan demikian dapat disimpulkan bahwa ada perbedaan yang nyata antara hasil belajar siswa dengan menggunakan efektivitas pembelajaran cooperatipe intregrated reading and compocition (CIRC) untuk meningkatkan pemahaman konsep belajar matematika pada materi persamaan linear dua variabel di kelas X SMA Negeri 2 Tor gamba Tahun Pelajaran 2017/2018.
\end{abstract}

Kata Kunci: Model Pembelajaran Cooperatipe Integrated Reading And Compocition (Circ), Pemahaman Konsep

\section{PENDAHULUAN}

Matematika sebagai salah satu bagian dari ilmu pengetahuan merupakan mata pelajaran yang diajarkan pada semua tingkat pendidikan dari jenjang pendidikan dasar sampai jenjang pendididikan tinggi. Pada masing-masing jenjang tersebut, banyak siswa yang mengalami kesulitan dalam mempelajari matematika. Bahkan wajar jika matematika tidak banyak disenangi orang, bahkan ada yang merasa takut.

Proses pembelajaran matematika di Indonesia hingga saat ini pada umumnya masih dilakukan dengan cara konvensional. Ciri-ciri dari pembelajaran matematika konvensional (ceramah) diantaranya berpusat pada guru. Guru lebih sering menjelaskan bahan belajar matematika melalui metode ceramah dan pemberian tugas (resitasi) sehingga siswa cenderung pasif, pertanyaan dari siswa jarang muncul, berorientasi pada satu jawaban yang benar dan aktivitas siswa yang sering dilakukan mencatat dan menyalin. Pembelajaran matematika dengan cara konvensional biasanya penyampaian guru bersifat monoton, hampir tanpa variasi kreatif.

Pendidikan merupakan persoalan penting bagi kemajuan suatu bangsa, dalam hal ini sekolah sebagai lembaga pendidikan merupakan tempat terjadinya proses pembelajaran yang diusahakan dengan sengaja untuk mengembangkan kepribadian dan segenap potensi siswa sehingga mereka dapat tumbuh dan berkembang sesuai dengan tujuan pendidikan nasional. Menurut Djamarah, (2016:23) Belajar adalah proses perubahan tingkah laku akibat dari interaksi dengan lingkungannya. Perubahan tersebut menyangkut perubahan pengetahuan, keterampilan, maupun sikap. Hasil belajar dapat dikatakan membekas atau konstan, jika perubahan yang terjadi akibat proses belajar tahan lama dan tidak terhapus begitu saja.

Proses pembelajaran khususnya matematika akan lebih efektif dan bermakna apabila siswa berpartisipasi aktif, dengan cara tidak menunjukkan sikap pasif di dalam kelas 
maupun di luar kelas. Tetapi sampai saat ini masih banyak terdengar keluhan bahwa mata pelajaran matematika membosakan, tidak menarik, memusingkan yang cenderung membuat siswa menjadi kurang merespon saat pelajaran berlangsung, bahkan ada siswa yang tidak masuk sekolah dikarenakan ada mata pelajaran matematika. Kenyataan ini adalah suatu persepsi negatif terhadap matematika.

Model Pembelajaran Kooperatif Tipe CIRC merupakan singkatan dari Cooperative Integrated Reading and Composition, termasuk salah satu model pembelajaran cooperative learning yang pada mulanya merupakan pengajaran kooperatif terpadu membaca dan menulis yaitu sebuah program komprehensif atau luas dan lengkap untuk pengajaran membaca dan menulis untuk kelas-kelas tinggi sekolah dasar. Slavin (2014:12)

Namun, Cooperative Integrated Reading and Composition (CIRC) telah berkembang pada pelajaran eksak seperti pelajaran matematika. Upaya meningkatan kualitas pendidikan merupakan salah satu fokus di dalam pembangunan pendidikan Indonesia dewasa ini. Salah satu pendekatan pemecahan berbagai permasalahan yang digunakan dalam rangka peningkatan kualitas pendidikan itu adalah pemanfaatan penelitian pendidikan. Seperti halnya pendidikan matematika yang juga perlu ditingkatkan kualitas pengajarannya. Dan tak lepas pula pembelajaran matematika di SMA selalu mengacu pada kurikulum pendidikan.

Demi kelancaran proses belajar mengajar guru harus bisa menggunakan metode yang tepat dipakai dalam menyampaikan materi. Berdasarkan penggunaan metode yang tepat diharapkan siswa tidak akan mengalami kesulitan untuk memahami konsep dan akhirnya bisa menggunakan ilmu matematika yang ia terima sebagai peran aktif dimasa mendatang. Namun ironisnya, dengan metode yang sesuai, masih saja hasil belajar yang dicapai pada pelajaran matematika masih rendah, sehingga menjadi sorotan bapak atau ibu guru di sekolah-sekolah. Kenyataan ini perlu mendapatkan perhatian yang serius dengan inovasi-inovasi yang konstruktif sehingga dapat memberikan harapan yang lebih bagus.

Matematika merupakan materi pelajaran yang diberikan kepada siswa SMA sebagai bekal agar dapat mengembangkan sikap dan kemampuan serta pengetahuan dan ketrampilan dasar, selain itu berperan pula sebagai sarana untuk mengetahui ilmu pengetahuan dan teknologi. Sistem pengajaran matematika perlu ditingkatkan dan disempurnakan sehingga siswa mampu menguasai materi pelajaran matematika dengan baik.

Dengan penguasaan materi matematika diharapkan siswa mempunyai sikap kritis, analitis, logis, cermat serta disiplin. Disamping mampu menerapkannya pada disiplin ilmu lain atau dalam kehidupan seharihari. Untuk itu guru diharapkan aktif dan kreatif dalam melaksanakan kegiatan belajar mengajar sehingga siswa mampu menguasai materi matematika dengan baik.

Berdasarkan observasi di SMA Negeri 2 Torgamba faktor lain yang menyebabkan rendahnya hasil belajar siswa adalah kurangnya minat belajar, kurang percaya diri dan takut bertanya bila kurang jelas, sehingga materi pelajaran sulit untuk dikuasai. Guru hanya menjelaskan saja, latihan soal pemecahan masalah kurang, tidak diberi tes perbaikan, terpaksa untuk mengejar target kurikulum. Oleh karena itu penelitian menitik beratkan pemberdayaan pembelajaran dengan model kooperatif ,dalam rangka membangun keberanian bertanya untuk mengatasi kesulitan belajar. Sehingga siswa lebih berminat belajar matematika, lebih percaya diri dan lebih mudah menguasai materi pelajaran matematika. Akibatnya hasil belajar siswa khususnya pelajaran matematika dapat meningkat.

Upaya saya agar meningkatkan belajar siswa dengan penerapan pembelajaran koperatif tipe CIRC (Cooperatipe Intregrated Reading And Compocition) adalah pengajaran dengan menggunakan metode kooperatif menjadi pilihan karena mempunyai banyak kelebihan. Misalnya dalam menyelesaikan permasalahan dapat dilakukan secara bersama-sama, sehingga anak dalam kelompok secara aktif terlibat menemukan permasalahan, relatif anak berani bertanya, lebih percaya diri, sehingga lebih mudah menguasai materi pelajaran matematika. Akibatnya prestasi belajar matematika dapat meningkat.

\section{METODOLOGI PENELITIAN}

Penelitian ini merupakan penelitian quasi-eksperimen (quasi experiment) dengan rancangan pretest-postest. Pada kelas eksperimen, peneliti memberi perlakuan pembelajaran dengan menggunakan model pembelajaran CIRC, yang bertujuan untuk melihat gejala atau dampak yang ditimbulkan 
pada siswa terkait dengan pemahaman konsep siswa. Lokasi penelitian ini dilaksanakan di SMA Negeri 2 Torgamba Kabupaten Labuhanbatu Selatan. Sampel pada penelitian ini adalah siswa kelas $X$. Instrumen yang digunakan dalam penelitian ini adalah tes kemampuan pemahaman konsep sebanyak 5 soal yang digunakan untuk pre-test dan post-test dan angket untuk melihat respon siswa terhadap Model CIRC. Analisis untuk pengujian hipotesis menggunakan uji t yaitu paired sample t test, namun sebelum dilakukan uji t terlebih dahulu dilakukan uji normalitas dan homogenitas dan menggunakan skala likert untuk menghitung angket.

\section{HASIL DAN PEMBAHASAN PENELITIAN}

\section{Hasil Penelitian}

\section{Analisis Data Instrumen Penelitian}

Data yang dikumpulkan peneliti dalam penelitian ini yaitu berupa data kemampuan koneksi matematis siswa yang diperoleh dengan menggunakan instrumen tes kemampuan koneksi matematis sebanyak 5 soal uraian yang diberikan sebagai tes awal (pre-test) dan tes akhir (post-test).

\section{Data Hasil Kemampuan Koneksi Matematis Siswa Kelas Eksperimen}

Data hasil pre-test dan post-test kemampuan koneksi matematis siswa kelas eksperimen dapat dilihat pada tabel 1 berikut ini:

Tabel 1. Data Pre-test dan Post-test Kelas Eksperimen

\begin{tabular}{|c|c|c|c|}
\hline Kode Siswa & Pre-test & Post-test & Gain \\
\hline $\mathrm{s}-1$ & 52 & 74 & 22 \\
\hline $\mathrm{s}-2$ & 36 & 66 & 30 \\
\hline $\mathrm{s}-3$ & 35 & 56 & 21 \\
\hline $\mathrm{s}-4$ & 36 & 58 & 22 \\
\hline $\mathrm{s}-5$ & 54 & 50 & -4 \\
\hline $\mathrm{s}-6$ & 43 & 67 & 24 \\
\hline $\mathrm{s}-7$ & 40 & 57 & 17 \\
\hline $\mathrm{s}-8$ & 46 & 52 & 6 \\
\hline $\mathrm{s}-9$ & 50 & 48 & -2 \\
\hline $\mathrm{s}-10$ & 36 & 49 & 13 \\
\hline $\mathrm{s}-11$ & 33 & 71 & 38 \\
\hline
\end{tabular}

\section{Analisis Data Hasil Penelitian}

a. Perhitungan Mean (rata-rata) dan simpangan baku hasil belajar siswa.

Rata-rata dan simpangan baku hasil belajar siswa yang diberi pengajaran dengan menggunakan pembelajaran Cooperatipe Intregrated Reading And Compocition (CIRC) adalah:
0,89

$$
\text { Pre-tes : } \overline{X_{1}}=5,4 \quad \mathrm{~S}_{1}=
$$

$$
\text { Pos-tes : } \overline{X_{1}}=8,8 \quad \mathrm{~S}_{1}=
$$

Rata-rata simpangan baku hasil belajar siswa yang diberi pengajaran dengan menggunakan metode pembelajaran konvensional adalah: 
Vol.4, No.2 Nopember 2018

Hal $33-40$

0,76

$$
\text { Pre-tes : } \overline{X_{1}}=5,1
$$$$
\mathrm{S}_{1}=
$$

$$
\text { Pos-tes : } \overline{X_{1}}=7,7
$$$$
\mathrm{S}_{1}=
$$

\section{Uji Normalitas Data}

1. Untuk menguji normalitas data kemampuan siswa digunakan uji Liliefors. Dari hasil perhitungan kedua kelas yaitu nilai hasil belajar siswa yang diberi pengajaran dengan menggunakan strategi pembelajaran Cooperatipe Intregrated Reading And Compocition (CIRC) dikelas $X$ SMA Negeri 2 Torgamba untuk pre-tes diperoleh Lnitung $=0,100, L_{\text {tabel }}=0,140$ dan dengan menggunakan pembelajaran Cooperatipe Intregrated Reading And Compocition (CIRC) $X^{2}$ SMA Negeri 2 Torgamba untuk pre-tes diperoleh Lhitung $=$ 0,119 . Karena Lhitung $<$ Ltabel maka dapat disimpulkan bahwa kedua kelompok sampel berasal dari populasi berdistribusi normal. (lampiran).

2. Demikian juga hasil normalitas untuk hasil belajar siswa yang diberikan pengajaran dengan menggunakan metode konvensional. Dari hasil perhitungan untuk kedua kelas yaitu data nilai hasil belajar siswa yang diberikan dengan menggunakan metode konvensional dikelas $X^{3}$ SMA Negeri 2 Torgamba untuk pos-tes diperoleh $L_{\text {hitung }}=0,120$, L Label $=$ 0,140 dan untuk data nilai hasil belajar siswa yang diberi pengajaran dengan metode konvensional dikelas $x^{3}$ SMA Negeri 2 Torgamba untuk pos-tes diperoleh Lnitung $=0,111$, Ltabel $=0,140$. Karena Lnitung < Ltabel maka dapat disimpulkan bahwa kedua kelompok sampel berasal dari populasi berdistribusi normal (lampiran).

\section{Uji Homogenitas}

Dari hasil perhitungan pada lampiran 13, diperoleh bahwa harga $F_{\text {hitung }}$ Pre-tes = 1,18 . Setelah membandingkan harga $F_{\text {hitung }}$ Pos-tes $=1,63$ dengan harga $F_{\text {tabel }}$ dan pada taraf nyata $\alpha=0,05$ diperoleh $F_{\text {tabel }}=1,71$. Ternyata $F_{\text {hitung }}<F_{\text {tabel}}$, berarti hasil belajar siswa yang diberi dengan pembelajaran Cooperatipe Intregrated Reading And Compocition (CIRC) dan metode konvensional mempunyai varians yang sama (homogen).

\section{Pengujian Hipotesis}

Telah diketahui bahwa kedua kelompok data adalah berdistribusi normal dan mempunyai varians yang sama (homogen). Data yang digunakan untuk pengujian hipotesis ini adalah tes akhir belajar siswa. Pengujian hipotesis ini dilakukan dengan uji satu pihak dengan menggunakan uji statistik t.

Dari hasil perhitungan pada lampiran diperoleh thitung $=6,466$. Setelah membandingkan harga thitung dengan harga ttabel dengan taraf nyata $\alpha=0,01$ untuk daftar distribusi t diperoleh tabel $=2,856$, karena thitung tidak terletak diantara - 2,856 dan 2,856 maka Ho ditolak dengan kata lain $\mathrm{Ha}$ diterima. Dengan demikian dapat disimpulkan bahwa ada perbedaan yang nyata antara hasil belajar siswa dengan menggunakan efektivitas pembelajaran cooperatipe intregrated reading and compocition (CIRC) untuk meningkatkan pemahaman konsep belajar matematika pada materi persamaan linear dua variabel di kelas $X$ SMA Negeri 2 Tor gamba Tahun Pelajaran 2017/2018.

\section{Proses Jawaban Siswa}

Pada proses jawaban kelas eksperimen dan kelas kontrol bisa di lihat jawaban dari siswa pada saat mengerjakan soal pretest dan posttest, berikut ini proses dari jawaban siswa kelas $\mathrm{X}^{3}$ dan $\mathrm{X}^{2}$ :

\section{a. Kelas $X^{3}$ ( Kelas Eksperimen )}


Tabel 2. Proses Jawaban kelas eksperimen

\begin{tabular}{|c|c|c|}
\hline No. & Soal Pre test & Soal Post test \\
\hline 1. & $\begin{array}{l}\text { mat } \\
\text { Proses jawaban diatas siswa } \\
\text { menjawab soal dengan indikator } \\
\text { pemahaman yaitu benar tapi } \\
\text { masih mengalami kesulitan nilai } \\
\text { 2. }\end{array}$ & $\begin{array}{l}\text { roses jawaban diatas siswa } \\
\text { menjawab soal dengan indicator } \\
\text { pemahaman yaitu jawaban } \\
\text { benar dengn mengandung } \\
\text { konsep dengan nilai deskripsi } \\
\text { nilai } 4 \text {. }\end{array}$ \\
\hline 2. & 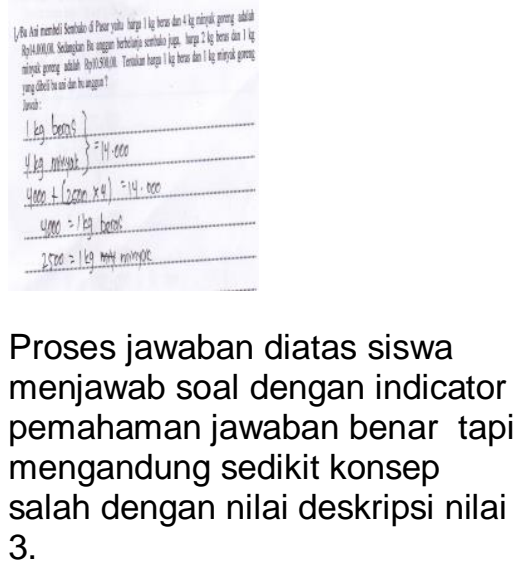 & 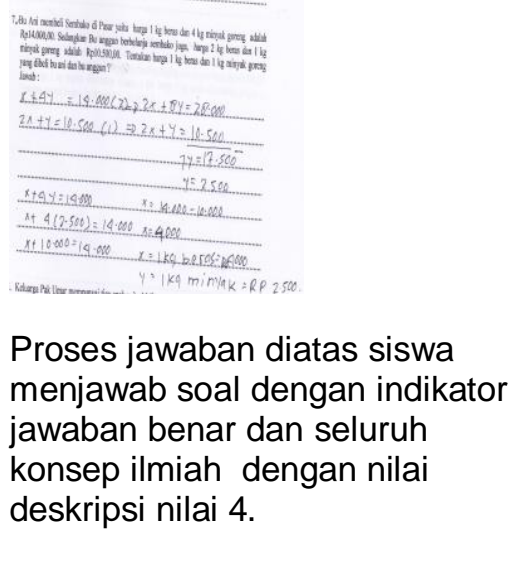 \\
\hline 3. & 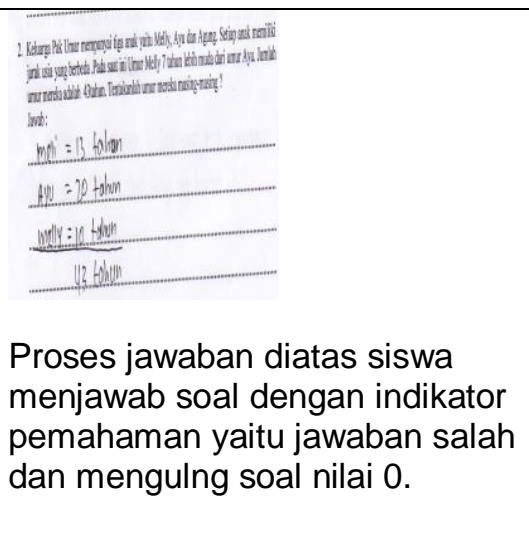 & $\begin{array}{l}\text { Proses jawaban diatas siswa } \\
\text { menjawab soal dengan indikator } \\
\text { pemahaman yaitu jawaban } \\
\text { benar tapi masih kurang konsep } \\
\text { nilai 3. }\end{array}$ \\
\hline
\end{tabular}


Vol.4, No.2 Nopember 2018

Hal $33-40$

\section{b. Kelas $\mathrm{X}^{2}$ ( Kelas Kontrol )}

Tabel 3. Proses Jawaban kelas kontrol

\begin{tabular}{|c|c|c|}
\hline No. & Soal Pre test & Soal Post test \\
\hline 1. & 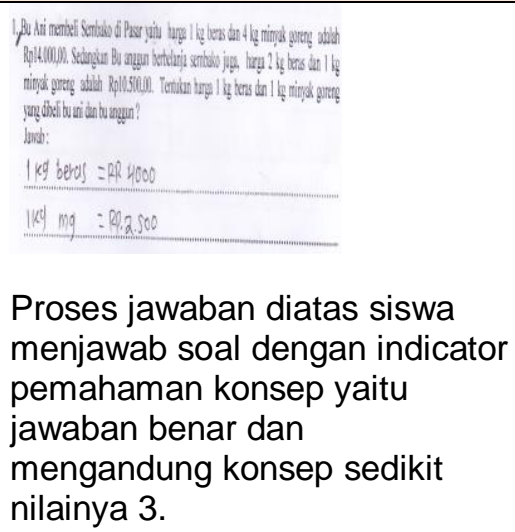 & 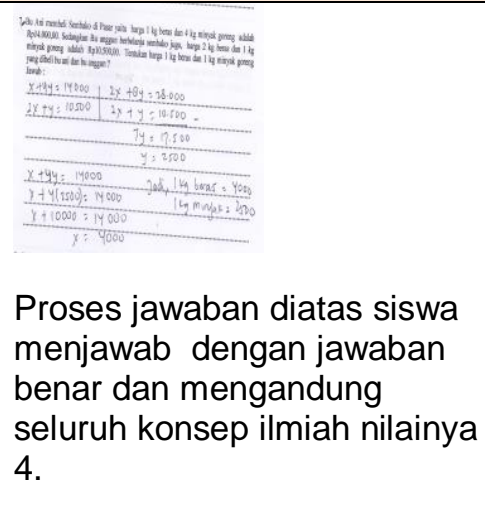 \\
\hline
\end{tabular}

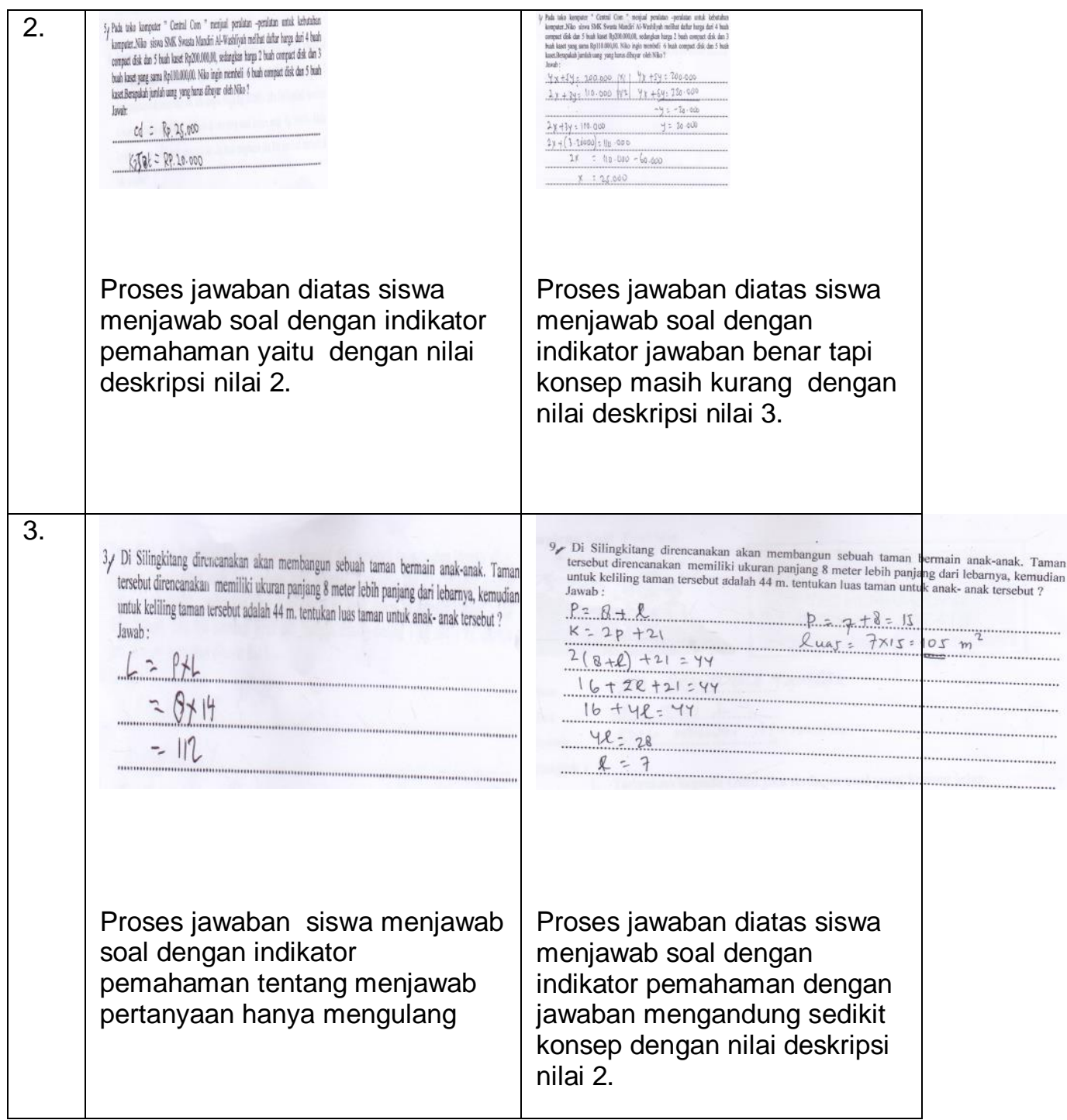




\section{Kesimpulan}

Berdasarkan pengolahan data dan pengujian hipotesis maka dalam penelitian ini dapat ditarik kesimpulan:

1. Hasil belajar siswa yang diberikan pengajaran dengan menggunakan Pembelajaran Cooperatipe Intregrated Reading And Compocition (CIRC) lebih baik dari pada hasil belajar siswa yang diberikan pengajaran dengan metode konvensional pada materi persamaan linear dua variabel Di Kelas X SMA Negeri 2 Torgamba Tahun Pelajaran 2017/2018.

2. Nilai rata-rata belajar dengan menggunakan Pembelajaran Cooperatipe Intregrated Reading And Compocition $(\mathrm{CIRC})=8,9 \pm 0,52$ dan nilai rata-rata siswa pada pengajaran dengan metode konvensional $=7,7 \pm$ 0,85 . Dari perbedaan nilai rata-rata pada taraf nyata $\alpha=0,05$ menunjukkan bahwa nilai rata-rata siswa yang menerima pengajaran dengan menggunakan Pembelajaran Cooperatipe Intregrated Reading And Compocition (CIRC) lebih tinggi dari pada nilai rata-rata siswa yang diberi pengajaran dengan metode konvensional, dengan demikian hasil belajar siswa yang diberi pengajaran dengan menggunakan Pembelajaran Cooperatipe Intregrated Reading And Compocition (CIRC) lebih baik dari pada hasil belajar siswa yang diberi pengajaran dengan menggunakan metode konvensional pada materi persamaan linear dua variabel di kelas $X$ SMA Negeri 2 Torgamba Tahun Pelajaran 2017/2018.

\section{DAFTAR PUSTAKA}

Arikunto. 2002. Populasi dalam Suatu Penelitian. Bina Aksara, Jakarta.

Bloom dalam Russefendi. 2010. Klasifikasikan Pemahaman. Penerbit Alfabeta, Bandung.

Djamarah. 2016. Proses Kegiatan Belajar. . Rineka Cipta. Jakarta.

Engstrom. 2012. Sintaks Implementasi Pembelajaran Kooperatif Tipe CIRC. Penerbit Alfabeta, Bandung.
Forgati. 2011. Implementasi Pembelajaran Kooperatif Tipe CIRC.PT. Raja Grafindo. Bandung.

Ibrahim, 2000. Manfaat Strategi Pembelajaran Kooperatif, Yudhistira, Jakarta.

Khairunisa. 2011. Upaya Peningkatan Kemampuan Komunikasi Belajar Matematika Melalui Cooperatif Integrated Reading and Composition (CIRC) Pada Materi Ajar Lingkaran Di Kelas VIII SMP Negeri 2 Rantau Utara Tahun pembelajaran 2011/2012.

Linda Lundgren, 2000. Strategi pembelajaran kooperatif, Remaja Rosdakarya, Bandung.

Michener dalam Herdian. 2010. Pemahaman Merupakan Salah Satu Aspek dalam Taksonomi Bloom. Bina Aksara, Jakarta.

Nurjannah. 2010. Upaya Peningkatan Kemampuan Komunikasi Belajar Matematika Melalui Cooperatif Integrated Reading and Composition (CIRC) Pada Materi Ajar Sistem Bilangan Bulat di VIII MTs. Negeri 2 Rantauprapat Tahun pembelajaran 2010/2011.

Rizky. 2009. Upaya Peningkatan Kemampuan Komunikasi Belajar Matematika Melalui Cooperatif Integrated Reading and Composition I(CIRC) Pada Materi Ajar Sistem Persamaan Linear Satu Variabel di Kelas VIII SMP Negeri 2 Rantau Selatan Tahun pembelajaran 2008/2009.

Slavin. 2014. Implementasi Pembelajaran Kooperatif Tipe CIRC.PT. Raja Grafindo. Bandung.

Suherman, 2014. Pembelajaran Kooperatif dalam Matematika, Remaja Rosdakarya, Bandung.

Steven, Slavin, 2014. Kooperatif Model pembelajaran Cooperative Integrated Reading and Composition (CIRC). Jemmars, Bandung.

Sudjana. 2012. Tes Peningkatan Pemahan Belajar Matematika. Penerbit Bumi Akasara. Jakarta. 
Jurnal Pembelajaran dan Matematika SIGMA (JPMS)

ISSN 2460-593X

Vol.4, No.2 Nopember 2018

Hal $33-40$

Tinto. 2012. Sintaks Implementasi

Pembelajaran Kooperatif Tipe CIRC.

Penerbit Alfabeta, Bandung. 